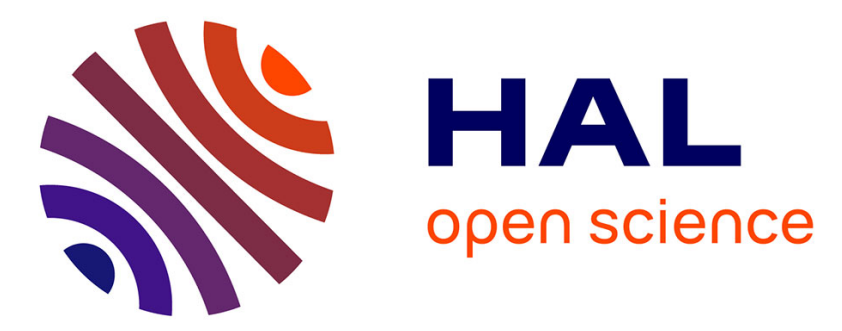

\title{
A method for assessing the influence of rainfall spatial variability on hydrograph modeling. First case study in the Cevennes Region, southern France
}

\author{
Isabelle Emmanuel, Olivier Payrastre, Hervé Andrieu, Félicien Zuber
}

\section{- To cite this version:}

Isabelle Emmanuel, Olivier Payrastre, Hervé Andrieu, Félicien Zuber. A method for assessing the influence of rainfall spatial variability on hydrograph modeling. First case study in the Cevennes Region, southern France. Journal of Hydrology, 2017, 555, pp.314-322. 10.1016/j.jhydrol.2017.10.011 . hal-01891908

\author{
HAL Id: hal-01891908 \\ https://hal.science/hal-01891908
}

Submitted on 10 Oct 2018

HAL is a multi-disciplinary open access archive for the deposit and dissemination of scientific research documents, whether they are published or not. The documents may come from teaching and research institutions in France or abroad, or from public or private research centers.
L'archive ouverte pluridisciplinaire HAL, est destinée au dépôt et à la diffusion de documents scientifiques de niveau recherche, publiés ou non, émanant des établissements d'enseignement et de recherche français ou étrangers, des laboratoires publics ou privés. 
A method for assessing the influence of rainfall spatial variability on hydrograph modeling. First case study in the Cevennes Region, southern France

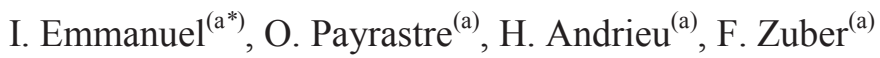

${ }^{(a)}$ PRES L'UNAM, IFSTTAR, Département GERS, Laboratoire Eau et Environnement, Bouguenais, France

${ }^{*}$ Corresponding author: Isabelle Emmanuel, Ifsttar Nantes, Département GERS, LEE, Route de Bouaye, CS4, 44341 Bouguenais Cedex, France.

e-mail: isabelle.emmanuel@ifsttar.fr, Telephone: +33 181668081

\title{
Abstract:
}

Emmanuel et al. (2015) proposed rainfall variability indexes intended to summarize the influence of spatial rainfall organization on hydrograph features at the catchment outlet. The present article shows how the proposed indexes may be used in a real-world case study to analyze the influence of spatial rainfall organization on hydrograph modeling. The selected case study is located in the Cevennes Region of southeastern France. The proposed methodology is as follows: the tested flow events are split into two subsets according to the values of their rainfall variability indexes; then, a comparison is drawn between modeled and measured hydrographs separately for each subset. The results obtained suggest that, on average, modeling results based on high-resolution rainfall data are improved for the subset whose rainfall variability influence is expected to be significant according to index values. Though limited to a relatively small number of hydrographs, this case study can be viewed as a first confirmation that the proposed method, based on the rainfall variability indexes of Emmanuel et al. (2015), is pertinent to investigating the influence of spatial rainfall variability on hydrograph modeling results.

Keywords: Spatial rainfall variability, Radar, Spatial rainfall indexes, Hydrograph modeling. 


\section{Highlights:}

27 We illustrate one use of rainfall variability indexes in real-world case studies

28 We perform a case-study based in France's Cevennes Region

29 Events were split into two subsets according to rainfall variability indexes

30 The indexes predict events for which high resolution rainfall improves outflow modeling. 


\section{Introduction}

What is the actual influence of spatial rainfall variability on the hydrograph at the catchment outlet? Interest in answering this question has been growing thanks to both the increasing availability of weather radar data and the development of distributed hydrological models. This topic is relevant for both research and practical reasons. On the research side, it contributes to a better understanding of how the spatial variability of rainfall propagates up to the catchment outlet depending on catchment features and, therefore, on the development of adapted modeling strategies. On the operational side, hydrological systems managers would benefit from knowing the conditions under which spatiallydetailed knowledge of rainfall and the incorporation of this information into hydrological models may lead to more accurate flood modeling results. Unfortunately, the literature on this topic has revealed contrasting conclusions.

The following sample of studies, performed in various contexts and based on various approaches, has concluded that the spatial variability of rainfall exerts a significant impact on modeling results at the catchment outlet: Anquetin et al. (2010), Bedient et al. (2000), He et al. (2013), Looper and Vieux (2012), Sangati et al. (2009), Sik Kim et al. (2008), Smith et al. (2007), Vieux et al. (2009), and Zoccatelli et al. (2010). Other studies have ascribed a more limited influence to this spatial variability: Adams et al. (2012), Brath et al. (2004), Cole and Moore (2008), Nicotina et al. (2008), Schuurmans and Bierkens (2007), Smith et al. (2004), and Tarolli et al. (2013); whereas the following studies have observed both influences: Pokhrel and Gupta (2011) confirmed the findings of Obled et al. (1994), according to which the influence of the spatial variability of rainfall fields on hydrographs at the catchment outlet can be greatly diminished by the damping effect of routing, thus making the variability difficult to detect. On the basis of 181 French catchments, Lobligeois et al. (2014) concluded that a detailed mapping of rainfall fields would be useful for hydrograph modeling in southern France, a region characterized by rainfall fields with a high degree of spatial variability, but not so useful in western France, where catchments are forced by rainfall fields with less spatial variability. Segond et al. (2007) analyzed an extensive and detailed dataset from the 1,400-km² Lee catchment in the U.K. (15 years of radar data, 16 rain gauges and 12 flow stations); they concluded 
that "results show a complex picture", with the influence of spatial rainfall variability being uncorrelated with either catchment scale or response time. In the field of urban hydrology, several studies using different approaches have addressed the influence of spatial rainfall variability on the rainfall runoff modeling of small catchments (i.e. approx. $10 \mathrm{~km}^{2}$ ); these studies have: proposed a temporal and spatial rainfall resolution adapted to Mediterranean events (Berne et al., 2004), and analyzed both the influence of rainfall uncertainty (Schellart et al., 2012) and the small-scale variability of rainfall (Gires et al., 2012). In sum, it appears that the influence of spatial rainfall variability on hydrograph modeling results depends on a combination of factors, namely: rainfall patterns, catchment characteristics, and runoff generation processes. This question remains an open research subject.

The present paper contributes to assessing the influence of spatial rainfall variability on hydrograph modeling results by pursuing the work developed in Emmanuel et al. (2015). Based on a simulation approach, these authors identified the conditions under which the spatial variability of rainfall plays a significant role, and they proposed indexes summarizing the influence of spatial rainfall organization on modeled outflow. This paper illustrates how such indexes may be used in a real-world case study for an in-depth analysis of the relation between spatial rainfall variability and modeling results; the case study is situated in the Cevennes Region of southeastern France.

The article is organized as follows. Section 2 presents the methodology proposed to assess the influence of spatial rainfall variability on modeling results. Section 3 exposes the Cevennes case study selected to test this method. Next, Section 4 describes the results obtained, while Section 5 offers a discussion of these results. Lastly, Section 6 provides a conclusion on this work.

\section{Methodology to identify the influence of spatial rainfall variability on hydrograph modeling}

Rainfall-runoff modeling (Renard et al., 2010) is affected by four sources of error: a) errors in rainfall estimates, b) errors in outflow estimates, c) imperfect representation of processes by hydrological models, and d) a miscalibration of model parameters. The combination of these sources of error with influential factors makes it difficult to isolate the influence of spatial rainfall variability, which 
requires a specific approach. Moreover, it would be helpful for this approach to be applicable to a wide variety of situations in terms of rainfall event features, catchment features and hydrological modeling. Given this context, the following method is being proposed to identify the influence, and this influence alone, of spatial rainfall variability on rainfall-runoff modeling (define as the outflow modeling at the catchment outlet).

We consider a set of observed hydrographs, with this set being as broad as possible so as: i) to be representative of varied catchments and rain conditions, and ii) to allow for a statistical analysis differentiating the influence of spatial rainfall variability from the other sources of error.

- This set of observed hydrographs is studied by comparing two contrasted rainfall scenarios, i.e.: 1) a fully spatially distributed rainfall assumed to represent the reference situation, and 2) a spatially uniform rainfall equal to the mean value of rainfall over the catchment. The rainfall-runoff model with these two scenarios yields two modeled hydrographs that can be compared to the observed hydrograph, thus providing information on the influence of spatial rainfall variability.

- In order to isolate the influence of spatial rainfall variability from the other sources of error, the set of observed hydrographs must be split into subsets as homogeneous as possible with regard to this influence. In assuming that the statistical characteristics of sources of error (b), (c) and (d) are independent of this influence, it is expected that the modeling results obtained on the subsets only differ for rainfall variability reasons.

- The splitting of the hydrograph set is based on the rainfall variability indexes proposed by Emmanuel et al. (2015); these indexes summarize the expected influence of spatial rainfall variability on the catchment response. In addition, since the indexes have been defined from rainfall fields and catchment characteristics, they are fully independent of the used model.

\subsection{Presentation of the rainfall variability indexes used}

Emmanuel et al. (2015) proposed rainfall spatial variability indexes specifically designed to detect situations for which this variability could exert great influence on the catchment response. They 
concluded that the proposed indexes offer a similar quantification of the impact of spatial rainfall variability on hydrograph peak time as those developed by Zoccatelli et al. (2010, 2011), yet they explain the impact on hydrograph magnitude slightly better.

These indexes are based on a comparison between the catchment width function and the rainfall width function. The catchment width function $w(x)$, defined as the portion of the catchment area at a flow distance $x$ from the outlet (Rodríguez-Iturbe and Rinaldo, 1997), is representative of the spatial structure of the catchment (and implicitly of the catchment response for a spatially homogeneous rainfall). This function is intrinsic for a given catchment. The rainfall width function, denoted $\mathrm{w}_{\mathrm{P}}(\mathrm{x})$, is defined as the proportion of rainfall on the catchment falling at a flow distance $x$ from the outlet; it combines information on spatial rainfall organization with catchment structure. The influence of spatial rainfall organization on the hydrological response is assessed by comparing the two width functions in their cumulative distribution form. As shown in Figure 1, the first index, denoted VG, is defined as the absolute value of the maximum vertical difference between the two width functions. The second index, denoted HG, is then defined as the corresponding difference between both width functions divided by the length of the longest hydrological path of the catchment. VG values close to zero indicate a rainfall distribution over the catchment displaying weak spatial variability. The higher the VG value, the more concentrated the rainfall over a small part of the catchment. HG values close to 0 reflect a rainfall distribution either concentrated near the catchment centroid position or spatially homogenous. Values less (greater) than 0 indicate that rainfall is distributed downstream (upstream).

The rainfall accumulation period suitable for variability index computation must be determined. Emmanuel et al. (2015) preconized computing the indexes on the raw rainfall accumulation observed just before the hydrograph peak, i.e. between $\left[T_{Q}-\alpha \operatorname{Tr} ; T_{Q}\right]$, with $\operatorname{Tr}$ being the catchment response time (usually defined as the time lag between the hydrograph and the hyetogram gravity centers), $T_{Q}$ the time of the hydrograph peak, and $\alpha$ lying in a [1.5 - 3] range with very low sensitivity to the $\alpha$ value within this range. For the case study therefore, a value of 3 has been set. 
Let's note that these indexes only partially explain the peak flow deviation due to the spatial variability of rainfall. It is easily understood that the two indexes summarizing this influence cannot replace a hydrological model.

[Figure 1 here]

\subsection{Sorting of hydrographs into subsets}

Smith et al. (2004) had already proposed splitting the tested set of hydrographs into two homogeneous subsets, namely: 1) events for which spatial rainfall variability is expected to exert a significant influence on the observed hydrograph at the catchment outlet; and 2) events for which this variability is expected to exert a weak influence.

In assuming the real existence of a continuum of situations between a negligible and a strong influence, we propose herein to proceed with this split based on a unique criterion $C\left(H_{i}\right)$ expressed as:

$C\left(H_{i}\right)=\frac{V G_{i}{ }^{2}}{V G_{a v}{ }^{2}}+\frac{H G_{i}^{2}}{H G_{a v}{ }^{2}}$

where $\left(\mathrm{VG}_{\mathrm{i}}, \mathrm{HG}_{\mathrm{i}}\right)$ are the rainfall variability indexes associated with hydrograph $\mathrm{Hi}$, and $V G_{a v}$ and $H G_{a v}$ are the mean index values for all tested hydrographs.

The value of $C\left(H_{i}\right)$ is expected to characterize the influence of spatial rainfall variability on the response of the considered catchment for hydrograph $H_{i}$. Since its value has been normalized by mean values $V G_{a v}$ and $H G_{a v}, C\left(H_{i}\right)$ represents the range of rainfall variability influence within the studied set of observed hydrographs.

The study of the statistical distribution of criterion $C(H)$ makes it possible to split the set of observed hydrographs into homogeneous subsets combining the hydrographs indicating a similar influence of spatial rainfall variability. It is clear that the number of subsets greatly depends on the variations in $C(H)$, as well as on the size of the studied set of observed hydrographs. 
158 The effects of information on spatial rainfall variability (i.e. high-resolution quantitative precipitation 159 estimates, or QPEs) on modeling results are assessed separately for each subset by comparing two 160 scenarios: 1) "distributed rainfall", whereby the hydrological model is forced by QPEs at the spatial resolution of available radar data, so as to obtain a so-called "distributed hydrograph"; and 2) "average

162 rainfall", whereby the hydrological model is forced by a spatially averaged rainfall field equivalent to the average rainfall intensity over the tested catchment. In this particular instance, the model yields a so-called "spatially averaged hydrograph" (called "average hydrograph" hereafter).

Each of the modeled hydrographs (distributed and average) is compared to the observed hydrograph; this comparison is intended to verify whether considering the information on spatial rainfall variability improves the reproduction of the catchment response to rainfall forcing.

The hydrograph comparison performed herein focused on peak flows, in accordance with two criteria: the level difference (denoted $\mathrm{L}_{\mathrm{Q}}$ ), and the time difference (denoted $\mathrm{T}_{\mathrm{Q}}$ ) between peaks, i.e.:

$L_{Q}=100\left(Q_{\max }-Q_{M}\right) / Q_{\max }$

$T_{Q}=100\left(T_{Q \max }-T_{Q \max M}\right) / T_{Q \max }$

with $Q_{\max }$ being the maximum value of the observed hydrograph, and $Q_{M}$ the associated value of the modeled hydrograph (distributed or average) at the same time. $T_{\text {Omax }}$ is the time of occurrence of $Q_{\max }$, while $T_{Q \max }$ is the time of occurrence of the maximum value of the modeled hydrograph (distributed or average).

\section{Case study}

\subsection{The Cevennes Region and the selected datasets}

The Cevennes Region encompasses a medium-elevation mountain range located in the southeastern part of the Massif Central zone (Fig. 2). The southeastern end of this range consists of a plateau and a 
plain area extending to the Mediterranean coast. The Cevennes Region displays typical Mediterranean climate and is subject to heavy rainfall events during the autumn season, causing flash floods that on occasion have resulted in considerable property damage and losses. Several rivers originate in the Cevennes Mountains and cross the intermediate plain area to empty into the Mediterranean Sea. The area considered in this study includes the catchments of three of these rivers: the Cèze, the Gardons, and the Vidourle (Fig. 2).

[Figure 2 here]

This region is covered by a network of rain gauges, at a density of roughly 1 gauge per every $150 \mathrm{~km}^{2}$, plus two weather radars providing quantitative precipitation estimates (QPEs) with high spatial $(1 \mathrm{~km}$ $\mathrm{x} 1 \mathrm{~km}$ ) and temporal (5 min) resolutions. Hydrometeorological recordings in this region also benefit from the presence of the Cevennes-Vivarais Mediterranean Hydrometeorological Observatory (Boudevillain et al., 2011), hereinafter referred to as OHMCV (http://www.ohmcv.fr). This long-term observatory intends to build an integrated hydrometeorological database of events in the CevennesVivarais zone that generate flash floods. The enhanced observation program conducted as part of the "Hymex-Mistrals" project has also significantly contributed to this data collection effort. The available operational datasets have therefore been submitted to a thorough quality control and can be considered of very good accuracy (Boudevillain et al., 2011). The OHMCV provides several QPE products.

For purposes of this study, we used hourly rainfall fields of $1 \mathrm{~km} \mathrm{x} 1 \mathrm{~km}$ spatial resolution obtained by the radar - rain gauge merging technique proposed by Delrieu et al. (2014); these fields offer a high level of accuracy compared to other QPE products. A time resolution of about 1/3 to $1 / 5$ the catchment response time (Berne et al., 2004) is required to reproduce flood dynamics in hydrograph modeling. This condition is satisfied for most of the considered catchments, even though the hourly time step may appear to be slightly too long for the smallest of them. Nevertheless, since the highly accurate QPE is only available at a one-hour time step, it has been adopted to simulate all hydrographs.

The studied area (Cèze, Gardons, and Vidourle catchments) includes 25 stream gauges adapted to high flow measurements and thus able to provide flood hydrographs of sufficiently good quality. These 25 
stream gauges define the outlets of the 25 basins considered in this study, with upstream catchment areas ranging from $42 \mathrm{~km}^{2}$ to $1,855 \mathrm{~km}^{2}$ (median value: $244 \mathrm{~km}^{2}$ ).

For purposes of this case study, the flood hydrographs were selected based on their unit peak flow, defined as $\mathrm{Q}_{\max } / \mathrm{S}^{0.8}$ (with $\mathrm{Q}_{\max }$ being the peak hydrograph flow and $\mathrm{S}$ the surface area of the upstream catchment). A threshold of $2.5 \mathrm{~m}^{3} / \mathrm{s} /\left(\mathrm{km}^{2}\right)^{0.8}$ was set to allow selecting just those rainfall events causing significant hydrological reactions. This point is important since the CINECAR hydrological model used herein was designed to model only this category of intense flood events.

213 During the 2007-2012 period selected for this study, 24 flood hydrographs related to 6 rainfall events reached a unit peak flow exceeding this threshold at one of the 15 stream gauges on the 25 present.

215 Table 1 lists the number of hydrographs recorded for each event, along with the mean rainfall 216 accumulations for the associated catchments and the mean surface area of these catchments, some of 217 which (but not all) are embedded. In case of embedded catchments the drainage areas sufficiently differ to consider that the results should not be highly correlated. In the following discussion, the embedded catchments are therefore assumed to be independent.

\begin{tabular}{|c|c|c|c|}
\hline Event date & $\begin{array}{c}\text { Flow gauging } \\
\text { station }\end{array}$ & $\begin{array}{c}\text { Total rainfall on } \\
\text { the catchment } \\
(\mathrm{mm})\end{array}$ & $\begin{array}{c}\text { Catchment surface } \\
\text { area }\left(\mathrm{km}^{2}\right)\end{array}$ \\
\hline 19 October 2008 & 13990 & 166 & 212 \\
\hline & 11313 & 190 & 665 \\
\hline & 11201 & 161 & 832 \\
\hline & 11861 & 131 & 1111 \\
\hline 31 October 2008 & 10749 & 252 & 162 \\
\hline & 12492 & 329 & 544 \\
\hline & 12833 & 292 & 665 \\
\hline & 13113 & 242 & 665 \\
\hline & 11313 & 197 & 832 \\
\hline & 11201 & 169 & 2111 \\
\hline & 11861 & 140 & 501 \\
\hline 29 December 2008 & 13990 & 138 & 621 \\
\hline & 14184 & 137 & 212 \\
\hline & 14983 & 133 & 212 \\
\hline & 13990 & 178 & \\
\hline & 13990 & 174 & \\
\hline
\end{tabular}




\begin{tabular}{|l|l|l|l|}
\hline & 14184 & 170 & 501 \\
\hline & 14983 & 158 & 621 \\
\hline & 16093 & 148 & 794 \\
\hline 1 November 2011 & 12320 & 513 & 220 \\
\hline & 12492 & 553 & 152 \\
\hline & 12676 & 512 & 246 \\
\hline & 12741 & 499 & 261 \\
\hline & 12833 & 496 & 543 \\
\hline
\end{tabular}

Table 1: Characteristics of the selected hydrographs

221

\subsection{The CINECAR model}

The distributed CINECAR hydrological model (Naulin et al., 2013; Versini et al., 2010) is based on a representation of the catchment as a ramified series of stream reaches, to which both left and righthand hillslopes are connected. For the sake of simplicity, the hillslopes are depicted by schematic rectangular shapes, and the river reaches are assumed to have a rectangular cross-section.

The Soil Conservation Service-Curve Number (SCS-CN) model is used to compute runoff rates and the corresponding effective rainfall on hillslopes at each computation time step. The effective rainfall is then propagated onto both the hillslopes and the downstream river network by either the kinematic wave model or the Hayami solution for the diffusive wave model (Moussa, 1996). The diffusive wave model is applied for flood wave attenuation on downstream river reaches with slopes of less than $0.6 \%$, while the kinematic wave model is applied for all other river reaches.

Since CINECAR was developed for the purpose of computing hydrographs in ungauged catchments, it features a very limited number of calibration parameters. The width of river reaches is the main parameter controlling the transfer function; and the Curve Number $(\mathrm{CN})$ value is the second key parameter and controls the temporal evolution of runoff rates. This model was applied in 2013 to the entire Cevennes Region (Naulin et al., 2013) in the aim of producing homogeneous results at the regional scale; for this reason, no real systematic or site-specific calibration was performed. Given that the channel widths could not be accurately estimated from available data, a fixed average channel width $w$ was used: $w=w_{o} \cdot i^{2}$, with $i$ being the Strahler order (Horton, 1945; Schumm, 1956) of the considered reach and $w_{o}$ an elementary width depending on the return period $T$ of the modeled 
discharge ( $w_{o}=4 \mathrm{~m}$ if $T<2$ years, $w_{o}=8 \mathrm{~m}$ if 2 years $<\mathrm{T}<10$ years, and $w_{o}=12 \mathrm{~m}$ if $T>10$ years). The Manning's $n$ roughness coefficients were assumed to be constant, with their values set at 0.05 for channels and 0.1 for hillslopes. The determination of $\mathrm{CN}$ values was based on the USDA method (USDA, 1986), as a function of land use and soil type (Corine Land Cover Database and European Soil Database), as well as of rainfall accumulation over the 5 preceding days.

This CINECAR model only depicts rapid runoff and does not include a continuous representation of base flow and soil moisture conditions. It is therefore not suited for modeling low-magnitude floods, which are highly dependent on initial conditions, but rather for modeling the rising limb and peak phases of large flood events. The application of this model to the Cevennes Region was validated with respect to measured data (Naulin et al., 2013). Satisfactory results were derived with an average Nash criterion computed for single flood events equal to 0.49. In addition, a comparative test between CINECAR and a GR4 lumped model (Perrin et al., 2003) was conducted for the Anduze stream gauge on the Gardon River, leading to the conclusion that both models performed similarly for the most intense events.

This same model version has been run herein without any adjustments. Based on the initial validation results, it can be considered that the model performs correctly for flood events whose peak discharges exceed $2.5 \mathrm{~m}^{3} / \mathrm{s} /\left(\mathrm{km}^{2}\right)^{0.8}$ : this threshold corresponds to significant (but not exceptional) flood events since it has been exceeded 25 times in 4 years within the considered region. The model's spatial resolution is determined by the hillslope dimensions: the 3 main catchments considered here (Cèze, Gardons, and Vidourle) were divided into 2,282 hillslopes, with a median surface area of $1.5 \mathrm{~km}^{2}$. The model can therefore be considered as well suited for taking into account high-resolution information on rainfall and the associated spatial variability often observed in the Cevennes Region.

\section{Results}

Due to the limited number of hydrographs (24), this sample can be split into two subsets, namely A and $\mathrm{B}$, by adopting a threshold value of $\mathrm{C}(\mathrm{H})=2$, as confirmed in Figure 3 . 
267 Among the 24 selected hydrographs, 9 were classified in subset A (with the influence of spatial 268 rainfall variability expected to be significant) and the other 15 hydrographs in subset B (with a weak 269 influence expected). Examples of rainfall accumulations on the tested catchments are shown in Figure 4. The associated hydrographs in Figure 5 display the variety of situations that can be encountered. For hydrographs B1 and B2, the hydrological model fails to perform adequately, and the modeling errors appear to be very large when compared to the weak influence of rainfall variability. For instance, for $\mathrm{B} 2$, rainfall accumulation is relatively uniform over the catchment, and the value of $\mathrm{C}\left(\mathrm{B}_{2}\right)$ lies close to 0 . The distributed and average hydrographs are very similar for this event. Conversely, for A1 and A2, the average rainfall results in an underestimation of the observed hydrograph, whereas the distributed rainfall enables to obtain a model peak value close to the observed value.

The distributions of level and time differences $\left(\mathrm{L}_{\mathrm{Q}}, \mathrm{T}_{\mathrm{Q}}\right)$ computed for the average and distributed hydrographs are compared in Figure 6 for both subsets A and B.

For subset $\mathrm{B}$, the distributions of computed $\mathrm{L}_{\mathrm{Q}}$ are very similar for the average and distributed hydrographs: the median values are respectively equal to $42.2 \%$ vs. $40.5 \%$, with the third quartile equal to $64.4 \%$ vs. $63.4 \%$. The distributions of $\mathrm{T}_{\mathrm{Q}}$ values are also similar, with median values equal to $26.8 \%$ vs. $19.2 \%$.

In contrast, for subset $\mathrm{A}$, the distributions of computed $\mathrm{L}_{\mathrm{Q}}$ seem to differ significantly between average and distributed hydrographs. The box plots are more differentiated, with median values respectively equal to $67.5 \%$ vs. $52 \%$, and the third quartile equal to $77.3 \%$ vs. $57.8 \%$. Such differences are also observed for $\mathrm{T}_{\mathrm{Q}}$ values, with median values equal to $48.2 \%$ vs. $29.2 \%$. 
This result reflects that subset A (regrouping events whose spatial rainfall variability is expected, according to the rainfall indexes, to exert a significant influence) is very different from subset $\mathrm{B}$ (events whose spatial rainfall variability is expected to exert a weak influence). For A, the use of distributed rainfall inputs enables to reduce the differences between modeled and observed hydrographs, which in turn confirms that the information on spatial rainfall variability deserves to be taken into account for these rainfall events. For subset B on the other hand, the use of distributed rainfall inputs does not improve hydrograph modeling at the catchment outlet than using average rainfall over the catchment.

Figure 6 also illustrates the usefulness of the two subsets A and B. It shows that if all the hydrographs are grouped (i.e. case $\mathrm{A}+\mathrm{B}$ ), the statistical distributions of $\mathrm{L}_{\mathrm{Q}}$ (and also $\mathrm{T}_{\mathrm{Q}}$ ), cannot be clearly distinguished between average and distributed hydrographs. Therefore, considering all the hydrographs together makes it difficult to identify the benefits associated with a detailed spatial resolution on rainfall.

Moreover, according to the events analyzed in this case study, the rainfall variability indexes proposed by Emmanuel et al. (2015) appear to be helpful in detecting situations where spatial rainfall variability exerts a significant influence on the shape of the hydrograph at the catchment outlet and where information on this variability (high-resolution QPEs) should yield significant improvements in hydrograph modeling results.

\section{Discussion}

\subsection{Position of the proposed method relative to former contributions}

As stated by Pokhrel and Gupta (2011): "there is a clear lack of consensus in the literature regarding the impacts of spatial distribution (of rainfall and parameters) on the streamflow response of a catchment", and this remains so despite the increasing number of studies. Several reasons make this topic a complicated one to address. Since all contributions to this question rely on hydrological modeling, the presence of various sources of error is capable of partially concealing the effect of spatial rainfall variability. The influential factors can never be taken into account in their entirety. For 
this reason, the contributions to this topic have adopted two distinct approaches, namely real-world case studies on one hand, and simulation studies aiming to avoid difficulties related to modelling errors. This second type of approach includes, for instance, an analysis of the variations in flow simulation due to rainfall field perturbations (Pokhrel and Gupta, 2011) or a comparison of spatial rainfall variability indexes and catchment dampening (Smith et al., 2004). The method proposed herein seeks to take advantage of rainfall variability indexes (initially developed based on simulation results), to facilitate the analysis of real-world case studies. The rainfall variability indexes are used to split the set of considered events into several homogeneous subsets in terms of the expected influence of spatial rainfall variability on modeling results. This influence is then evaluated separately on each subset in order to facilitate the analysis of modeling results.

Since this method is based solely on rainfall fields and catchment width function and response time, it remains completely independent of the hydrological modeling employed to produce the hydrographs initially. This specificity helps simplify method application and broaden its scope.

\subsection{Limitations of the approach}

The proposed method can be considered as a form of climatological analysis and thus requires a significant number of observations to reach a robust conclusion. In addition, the case study has focused on a given context (climatology, catchment features, etc.). These two aspects limit the significance of the conclusions drawn. Fortunately, the development of weather radar data for hydrological modeling and the increasing availability of weather radar databases should expand applications of the method to a variety of contexts in order to gain experience with the efficiency and robustness of the method. In particular, one key point of its application seems to be the statistical distribution of criterion $\mathrm{C}(\mathrm{H})$, which is used as the basis for splitting the set of observed hydrographs into homogeneous subsets. It would be interesting to learn more about this statistical distribution as a function of the considered context. Furthermore, the influence of spatial rainfall variability is not binary, i.e. weak vs. significant, but instead more continuous. Segmenting the dataset into a larger number of subsets would thus also be beneficial in capturing this continuity. 


\subsection{Possible future applications of the method}

344 Addressing the aforementioned issues would require applying the proposed method to a larger set of 345 case studies. More specifically, the method could now be used to complement the analysis of previous real-world studies, e.g. the study by Lobligeois et al. (2014), who performed a climatological analysis of the influence of spatial rainfall variability based on 3,620 flood events over 181 catchments.

In the future, the proposed method could also be used to compare several modeling approaches, including lumped and distributed models, instead of comparing two rainfall data scenarios with a distributed model. Based on this same procedure of separating hydrographs into subsets, a comparison of respective model performance in both situations might illustrate the advantages offered by a calibrated lumped model in situations of limited rainfall variability and moreover suggest how these advantages may be counterbalanced using a distributed model in the case of high rainfall variability.

Lastly, the classification method presented may help practitioners identify catchments for which the development of distributed rainfall-runoff modeling should be promoted, or where lumped models appear to be a good option thanks to a sufficiently limited rainfall heterogeneity. The separation of events into subsets may also be used to derive different parameter sets of lumped models, once again depending on the level of rainfall heterogeneity. Moreover, this separation step may be of great assistance in real-time applications, by identifying events whose high rainfall variability causes concerns over the validity of outflow predictions based on lumped models and thereby enabling a switch to distributed models (if available).

\section{Conclusion}

364 The objective of this study has been to present and test a method designed to identify the influence of spatial rainfall variability on hydrograph modeling results. This method makes use of the rainfall variability indexes developed by Emmanuel et al. (2015) in proposing a criterion representative of the expected influence of spatial rainfall variability on the hydrograph at the catchment outlet. The method 
has been tested on a case study grouping 24 hydrographs recorded on 15 catchments of various surface areas in the Cevennes Region (southeastern France) from 2008 to 2012. According to the spatial rainfall variability index values, the tested flood events were classified into two subsets, combining respectively: i) the hydrographs expected to be significantly affected by rainfall variability (subset A); and ii) the hydrographs expected to be weakly affected by this variability (subset B). Once examined, the modeling results revealed that on average the influence of taking spatial rainfall variability into account differs rather significantly for the two subsets: the added value is clear in the case of subset A, whereas the added value was not so evident in the case of subset B.

This case study has therefore illustrated the value of the proposed method in identifying the events for which the rainfall spatial variability should be taken into account for hydrograph modeling. The two spatial rainfall variability indexes used herein appear to be capable of detecting situations where spatial rainfall variability exerts a significant influence on catchment response. Their main advantage lies in a computation, based on the raw rainfall field and the catchment characteristics, thus making it possible to separate rainfall events independently of the model being tested. This separation step appears here to be of great benefit in better analyzing and understanding modeling results. It may prove helpful in a large number of practical applications, for in-depth analyses of lumped model performance and, if necessary, as support for the decision to switch to distributed modeling.

This study however needs to be extended to a much larger and more varied set of catchments and rainfall events in order to acquire a broader perspective on the influence of spatial rainfall variability.

\section{Acknowledgments}

The work presented in this paper has been supported by the SCHAPI (Service Central d'Hydrométéorologie et d'Appui à la Prévision des Inondations). The series of rainfall fields, derived from radar images, were provided by OHMCV (Guy Delrieu and Brice Boudevillain, LTHE). The authors acknowledge the Météo-France Agency for furnishing the radar and rainfall data, as well as the HyMeX database teams (ESPRI/IPSL and SEDOO/OMP) for their assistance in accessing the data. 
The authors are also very appreciative of the constructive comments received from reviewers, who contributed considerably to this paper.

\section{References}

Adams, R., Western, A.W., Seed, A.W., 2012. An analysis of the impact of the spatial variability in rainfall on runoff and sediment predictions from a distributed model. Hydrol. Process. 26, 3263-3280.

Anquetin, S., Braud, I., Vannier, O., Viallet, P., Boudevillain, B., Creutin, J.-D., Manus, C., 2010. Sensitivity of the hydrological response to the variability of rainfall fields and soils for the Gard 2002 flash-flood event. J. Hydrol. 394(1), 134-147. doi:10.1016/j.jhydrol.2010.07.002

Bedient, P.B., Hoblit, B.C., Gladwell, D.C., Vieux, B.E., 2000. NEXRAD Radar for Flood Prediction in Houston. J. Hydrol. Eng. 5(3), 269-277.

Berne, A., Delrieu, G., Creutin, J.-D. \& Obled, C.,2004. Temporal and spatial resolution of rainfall measurements required for urban hydrology. J. Hydrol. 299, 166-179.

Boudevillain, B., Delrieu, G., Bonnifait, L., Bouilloud, L., Kirstetter, P.E., Mosini, M.L., 2011. The Cévennes-Vivarais Mediterranean hydrometeorological observatory database. Water Resour Res. 47:W07701. http://dx.doi.org/10.1029/ 2010WR010353

Brath, A., Montanari, A., Toth, E., 2004. Analysis of the effects of different scenarios of historical data availability on the calibration of a spatially distributed hydrological model. J. Hydrol. 291, 232253, doi:10.1016/j.jhydrol.2003.1

Cole, S.J., Moore, R.J., 2008. Hydrological modelling using raingauge-and radar-based estimators of areal rainfall. J. Hydrol. 358(3), 159-181.

Delrieu, G., Wijbrans, A., Boudevillain, B., Faure, D., Bonnifait, L., Kirstetter, P.E., 2014. Geostatistical radar-raingauge merging: A novel method for the quantification of rain estimation accuracy. Adv. Water Resour. 71, 110-124, doi:10.1016/j.advwatres.2014.06.005 
Emmanuel, I., Andrieu, H., Leblois, E., Janey, N., Payrastre, O., 2015. The use of indexes to evaluate the influence of rainfall spatial variability on rainfall-runoff modelling: worth of a simulation approach? J. Hydrol. doi:10.1016/j.jhydrol.2015.04.058

Gires, A., Onof, C., Maksimovic', C` ., Schertzer, D., Tchiguirinskaia, I., Simoes, N., 2012. Quantifying the impact of small scale unmeasured rainfall variability on urban runoff through multifractal downscaling: a case study. J. Hydrol. 442, 117-128.

Horton, R.E., 1945. Erosional development of stream and their drainage basins; hydrophysical approach to quantitative morphology. Bulletin of the geological society of America, 56, 275-370.

He, X., Sonnenborg, T.O., Refsgaard, J.C., Vejen, F., Jensen, K.H., 2013. Evaluation of the value of radar QPE data and rain gauge data for hydrological modeling. Water Resour. Res. 49(9), 5989-6005.

Lobligeois, F., Andréassian, V., Perrin, C., Tabary, P., Loumagne, C., 2014. When does higher spatial resolution rainfall information improve streamflow simulation? An evaluation using 3620 flood events. Hydrol. Earth Syst. Sci. 18, 575-594.

Looper, J.P., Vieux, B.E., 2012. An assessment of distributed flash flood forecasting accuracy using radar and rain gauge input for a physics-based distributed hydrologic model. J. Hydrol. 412, 114-132.

Moussa, R., 1996. Analytical Hayami solution for the diffusive wave flood routing problem with lateral inflow. Hydrol. Process. 10, 1209-1227.

Naulin, J.P., Payrastre, O., Gaume, E., 2013. Spatially distributed flood forecasting in flash flood prone areas: Application to road network supervision in Southern France. J. Hydrol. 486, 88-99.

Nicotina, L., Alessi Celegon, E., Rinaldo, A., Marani, M., 2008. On the impact of rainfall patterns on the hydrologic response. Water Resour. Res. 44, W12401, doi:10.1029/2007WR006654.

Obled, C., Wendling, J., Beven, K., 1994. The sensitivity of hydrological models to spatial rainfall patterns: an evaluation using observed data, J. Hydrol. 159, 305-333. 
441

442

Renard, B., D. Kavetski, G. Kuczera, M. Thyer, and S. W. Franks, 2010. Understanding predictive uncertainty in hydrologic modeling: The challenge of identifying input and structural errors, Water Resour. Res., 46, W05521, doi:10.1029/2009WR008328.

Perrin, C., Michel, C., Andréassian, V., 2003. Improvement of a parsimonious model for streamflow simulation. J. Hydrol. 279, 275-289.

Pokhrel, P., Gupta, H.V., 2011. On the ability to infer spatial catchment variability using streamflow hydrographs. Water Resour. Res., 47, W08534, doi:10.1029/2010WR009873.

Rodríguez-Iturbe and Rinaldo, 1997. Fractal River basins. Chance and Self-Organisation. Press syndicate of the University of Cambridge, Cambridge, UK, 547 p.

Sangati, M., Borga, M., Rabuffetti, D., Bechini, R., 2009. Influence of rainfall and soil properties spatial aggregation on extreme flash flood response modelling: an evaluation based on the Sesia river basin, North Western Italy. Adv. Water Resour. 32(7), 1090-1106. doi : 10.1016/j.advwatres.2008.12.007

Schumm, S. 1956. Evolution of drainage systems and slopes in badlands at Perth Amboy, New Jersey. Bulletin of Geological Society of America, 67, 597-646.

Schellart, A. N. A., Shepherd, W. J., Saul, A. J., 2012. Influence of rainfall estimation error and spatial variability on sewer flow prediction at a small urban scale. Adv. Water Resour. 45 (0), 65-75.

Schuurmans, J. M., Bierkens, M. F. P., 2007. Effect of spatial distribution of daily rainfall on interior catchment response of a distributed hydrological model. Hydrol. Earth Syst. Sci., 11, 677-693.

Segond, M.-L., Wheater, H.S., Onof, C., 2007. The significance of spatial rainfall representation for flood runoff estimation: A numerical evaluation based on the Lee catchment, UK. J. Hydrol. 347, 116131.

Sik Kim, B., Kyung Kim, B., Soo Kim, H., 2008. Flood simulation using the gauge-adjusted radar rainfall and physics-based distributed hydrologic model. Hydrol. Process. 22, 4400-4414. doi: 10.1002/hyp.7043 

spatial variability in precipitation: an analysis of observed data. J. Hydrol. 298(1), 267-286. doi :10.1016/j.jhydrol.2004.03.039

469 Smith, J.A., Baeck, M.L., Meierdiercks, K.L., Miller, A.J., Krajewski, W.F., 2007. Radar rainfall 470 estimation for flash flood forecasting in small urban watersheds. Adv. Water Resour. 30(10), 20872097. doi :10.1016/j.advwatres.2006.09.007 organization and orographic control on flash flood response: the Weisseritz event of August 13, 2002.

474 J. Hydrol. Eng. 18(2), 183-193.

475 Versini, P.-A., Gaume, E., Andrieu, H., 2010. Application of a distributed hydrological model 476 to the design of a road inundation warning system for flash flood prone areas. Natural Hazards and 477 Earth System Sciences, 10, 805-817.

478 Vieux, B.E., Park, J.H., Kang, B., 2009. Distributed hydrologic prediction: sensitivity to accuracy of 479 initial soil moisture conditions and radar rainfall input. J. Hydrol. Eng. 14(7), 671-689. doi: $480 \quad 10.1061 /($ asce) he.1943-5584.0000039

481 Zoccatelli, D., Borga, M., Zanon, F., Antonescu, B., Stancalie, G., 2010. Which rainfall spatial 482 information for flash flood response modelling? A numerical investigation based on data from the 483 Carphatian range, Romania. J. Hydrol. 394(1-2), 148-161.

484 Zoccatelli, D., Borga, M., Viglione, A., Chirico, G.B., Blöschl, G., 2011. Spatial moments of 485 catchment rainfall: rainfall spatial organization, basin morphology and flood response. Hydrol. Earth 486 Syst. Sci. 15, 3767-3783. 


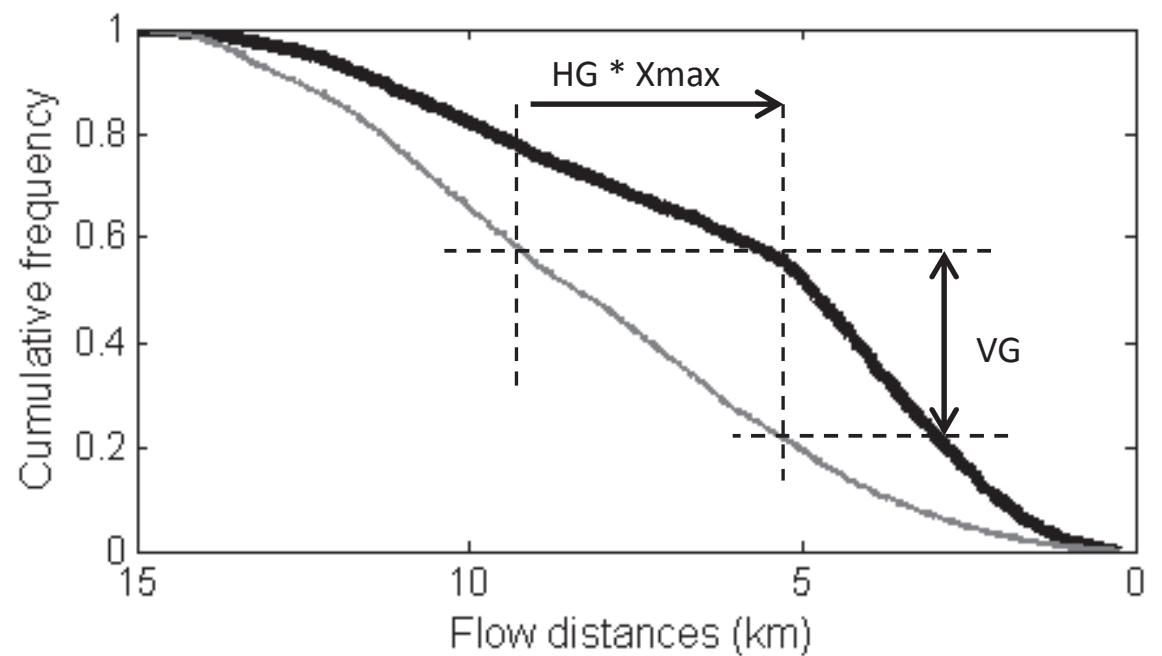

Flow distances (km) 


\section{Figure2}

Click here to download high resolution image

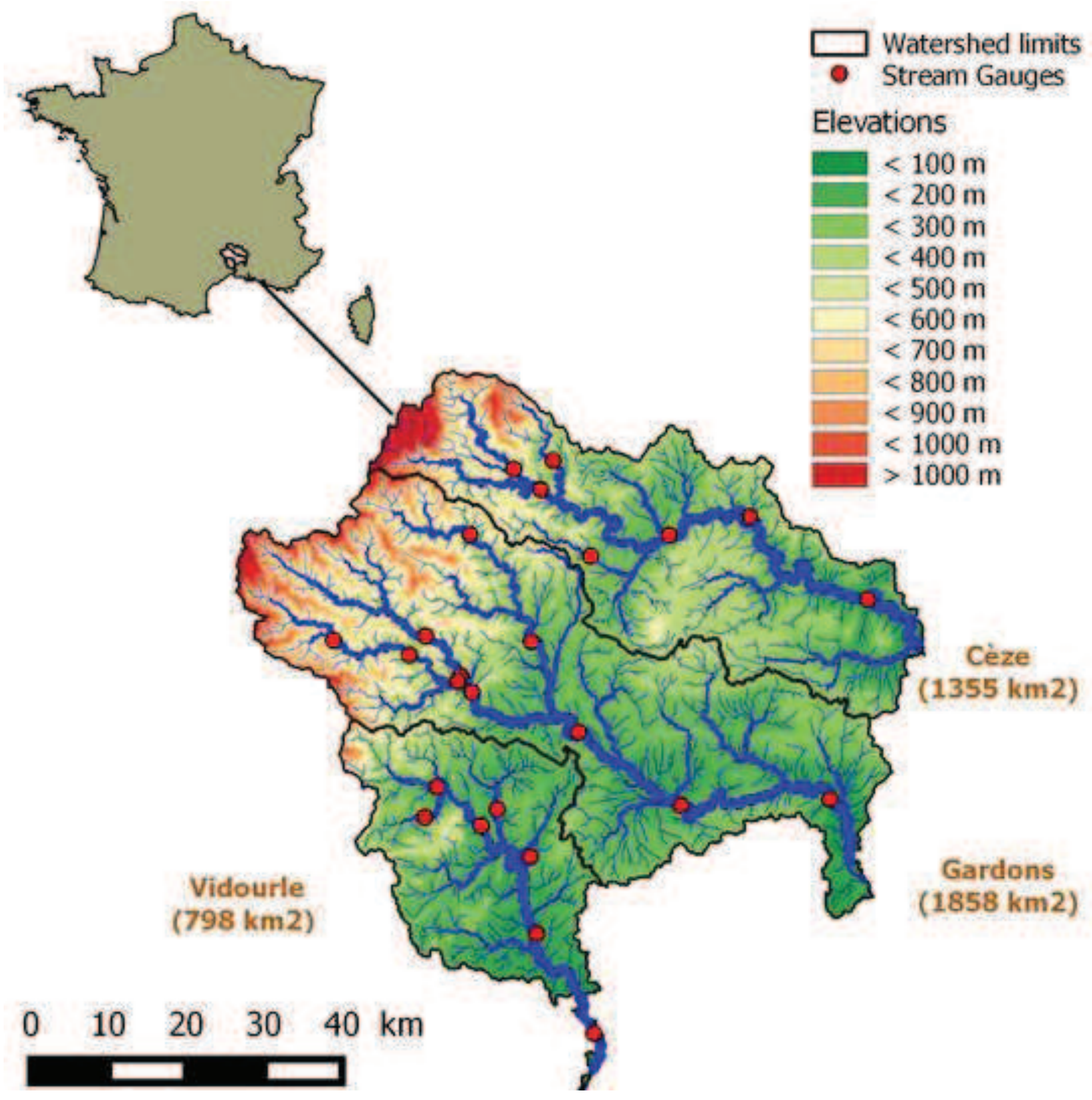




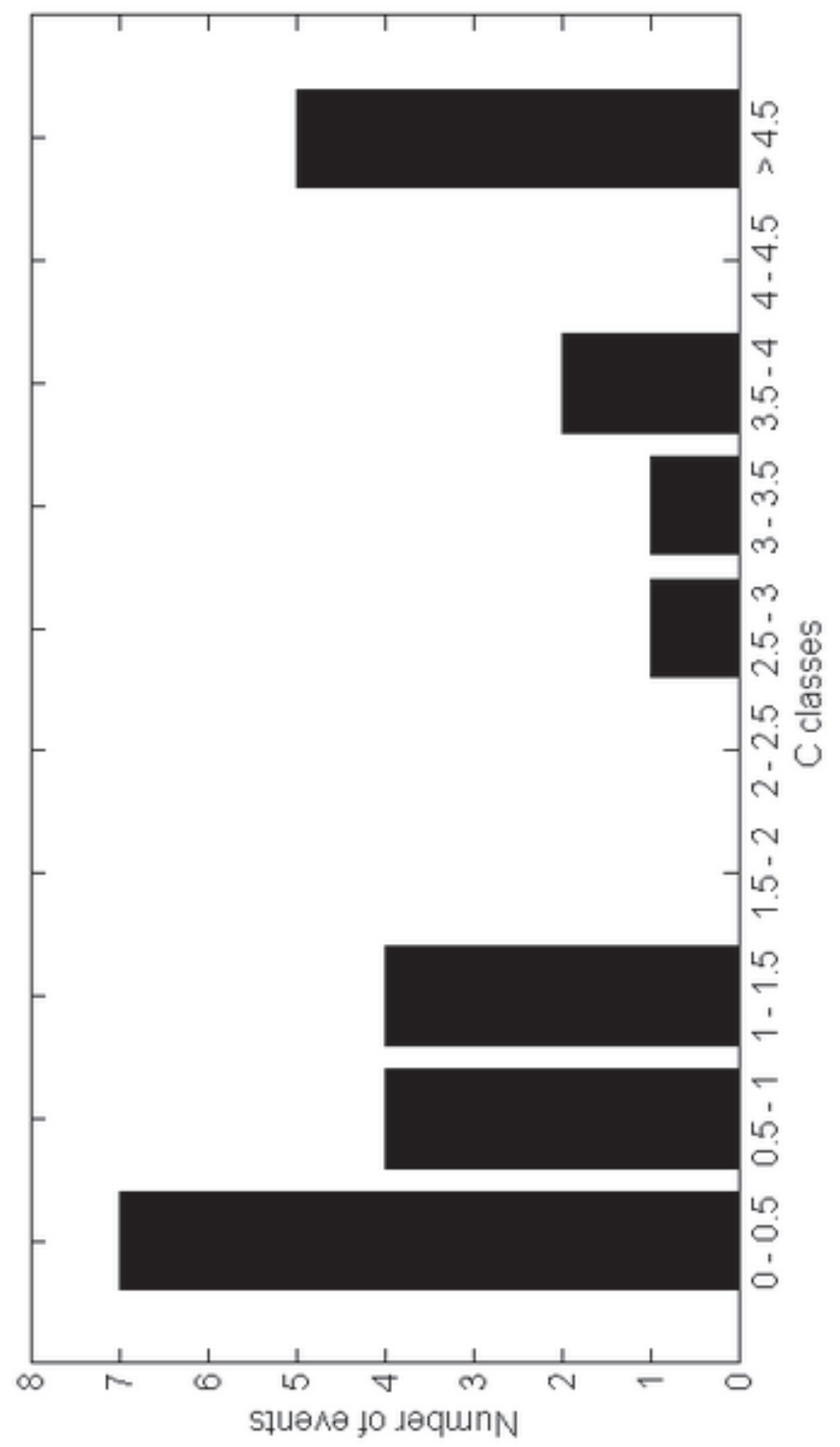

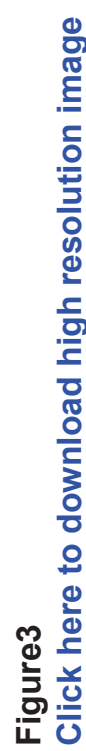




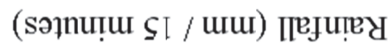

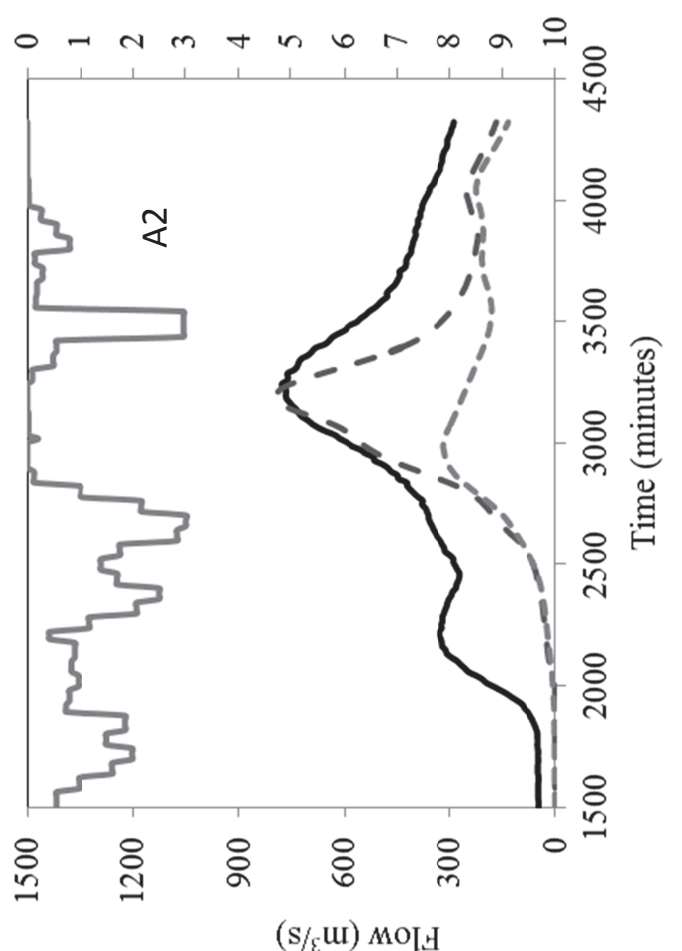

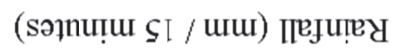

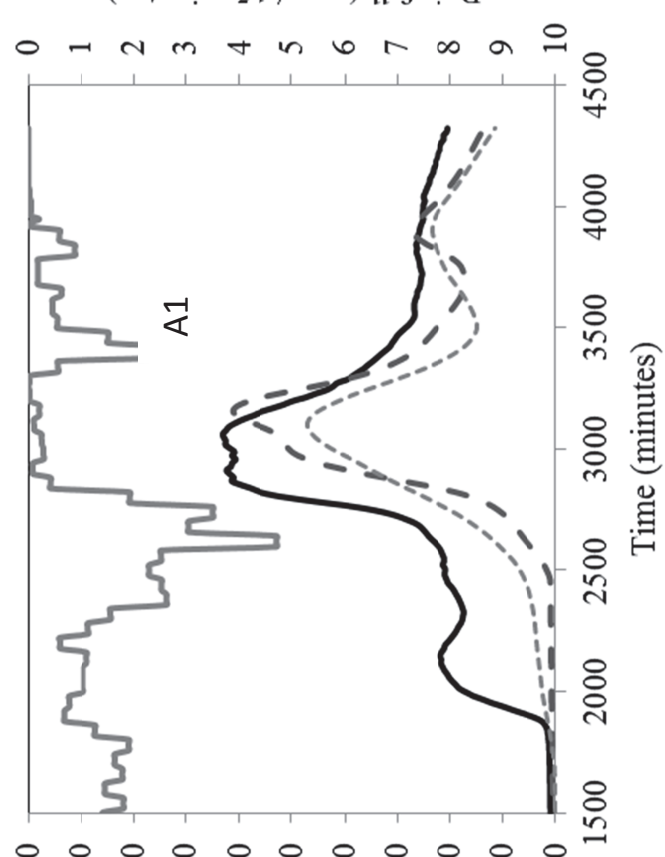

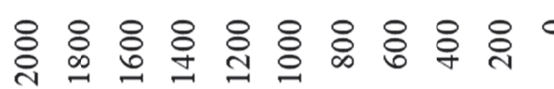

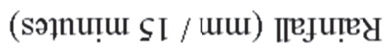

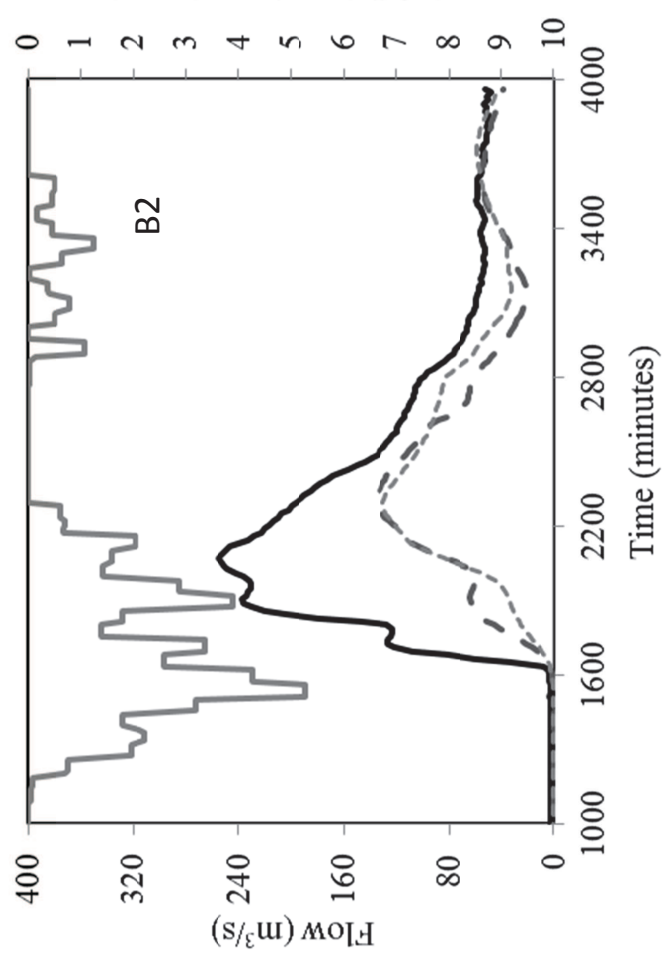

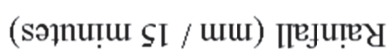

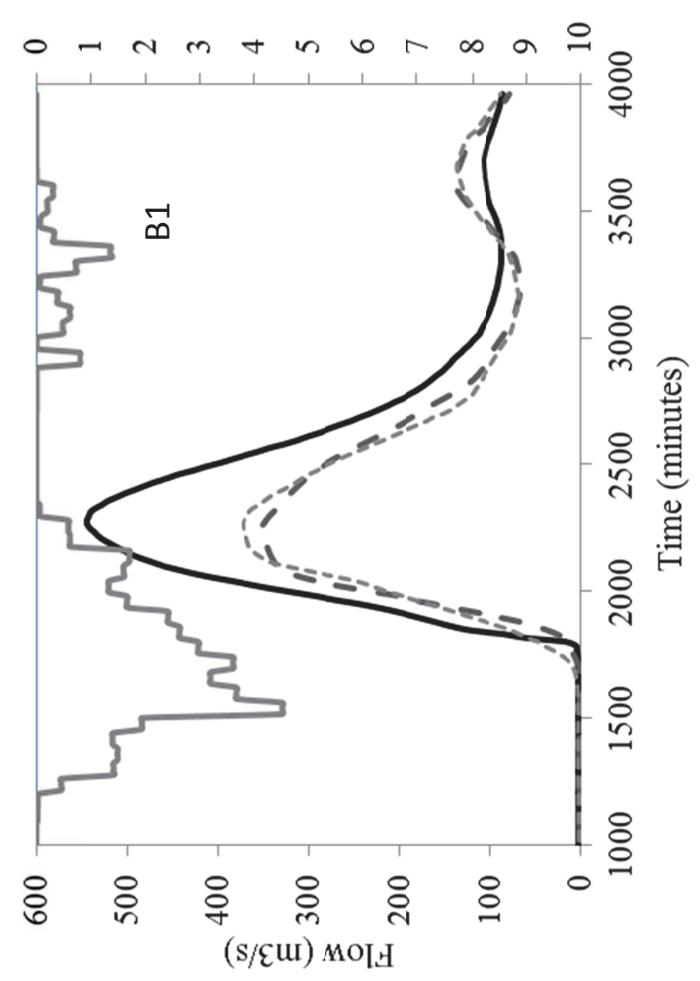





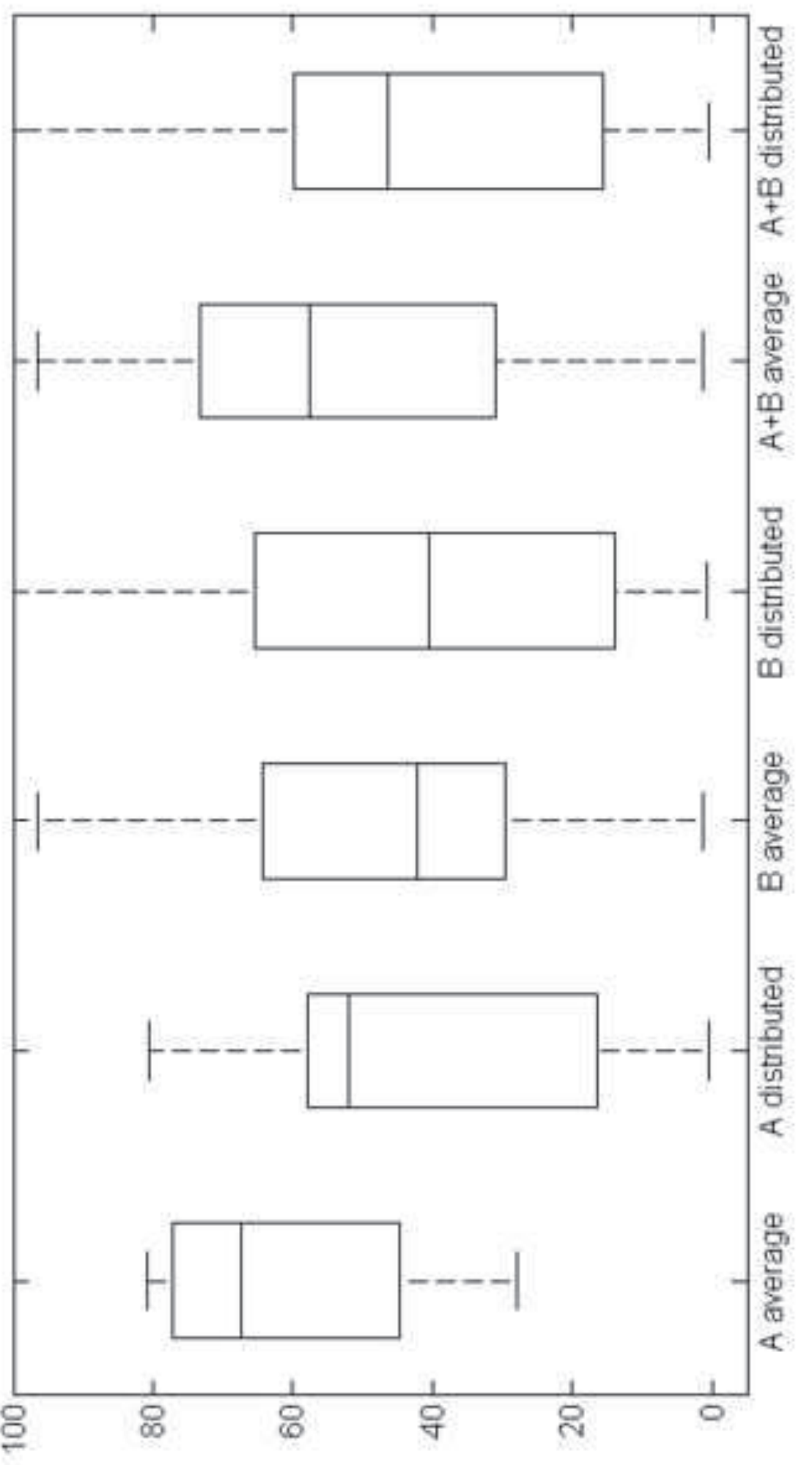

(\%) 07 


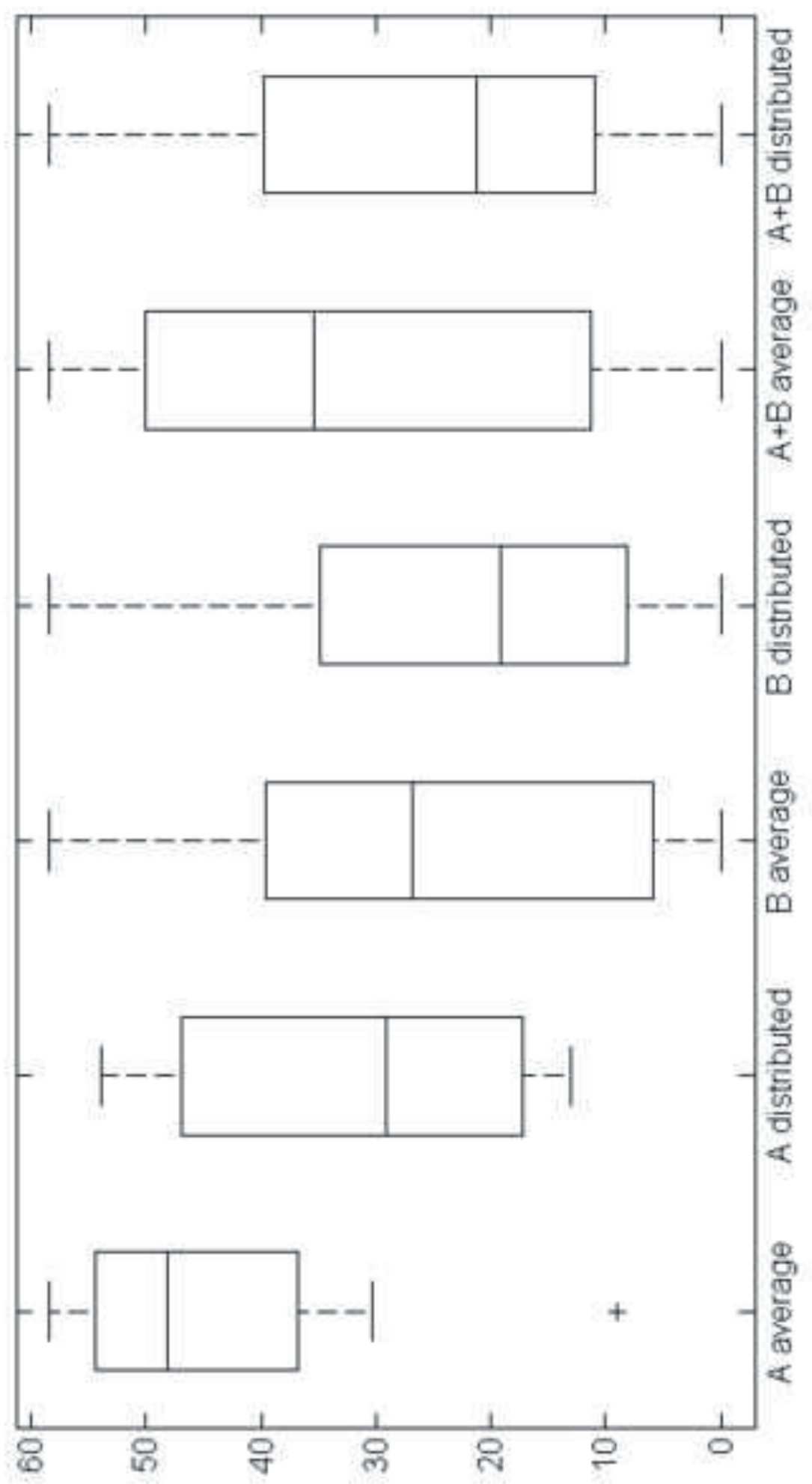

(\%) $0 \perp$ 


\section{Figure captions:}

Figure 1: Computation principle applied to rainfall variability indexes VG and $\mathrm{HG}$ based on the catchment width function (thin line) and rainfall width function (thick line). Xmax is the length of the longest hydrological path on the catchment.

Figure 2: Location of the tested catchments in the Cevennes Region (southeastern France)

Figure 3: Number of events per C classes.

Figure 4: Representation of rainfall accumulation (in $\mathrm{mm}$ ) computed over a $3 \operatorname{Tr}$ duration before the hydrograph peak, with Tr being the catchment response time. A1 and A2 occurred on 31 Oct 2008, over respectively a $1,096-\mathrm{km}^{2}$ and a $665-\mathrm{km}^{2}$ catchment with $C(A 1)=1.36$ and $C(A 2)=10.0$. B1 and B2 occurred on 29 Oct 2010, over respectively a $501-\mathrm{km}^{2}$ and a $212-\mathrm{km}^{2}$ catchment with $C(B 1)=0.23$ and $C(B 2)=0.06$.

Figure 5: Examples of comparisons between observed (solid line), distributed (dashed line) and average (dotted line) hydrographs. A1 and A2 are hydrographs classified in the "sensitive to spatial rainfall variability" sample. B1 and B2 are hydrographs classified in the "relatively insensitive to spatial rainfall variability" sample.

Figure 6: Comparison of the distributed and average modeled hydrographs to the observed hydrographs, based on the $\mathrm{L}_{\mathrm{Q}}(\mathrm{a})$ and $\mathrm{T}_{\mathrm{Q}}$ (b) criteria, for both subsets $\mathrm{A}$ and $\mathrm{B}$ and the entire $\mathrm{A}+\mathrm{B}$ dataset. The box plots represent the first quartile, median, third quartile and minimum and maximum values. An outlier has also been plotted individually (the "+" sign). 